\title{
Pluricentric Views towards English and Implications for ELT in China
}

\author{
Liang Jianli ${ }^{1}$ \\ ${ }^{1}$ Foreign Languages Department, Huizhou University, Huizhou, China \\ Correspondence: Liang Jianli, Foreign Languages Department, Huizhou University, Huizhou City, Guangdong \\ Province, China. E-mail: leanneliang@126.com
}

Received: January 6, 2015 Accepted: February 27, 2015 Online Published: March 25, 2015

doi:10.5539/elt.v8n4p90 URL: http://dx.doi.org/10.5539/elt.v8n4p90

\begin{abstract}
Descriptions of the classifications or models of English language have been proposed by a number of scholars who attempt to explain the differences in the ways English is used in different localities. This paper reviews three models of classification of English language, with an aim of drawing implications on how English Language Teaching (ELT) in China should adjust according to this highly pluricentric view towards English.
\end{abstract}

Keywords: ELT in China, pluricentricity, World Englishes

\section{Introduction}

As modern technologies such as the internet and 'apps' of all kinds increasingly facilitate communication and interaction between people, language contact phenomena become increasingly attractive to linguists. Meanwhile, as a result of education, 'bilingual speaker of English' has become a common attribute or characteristic for the majority of people all over the world, regardless of their first language background. The interface of these two trends is English, a focus of concern to critical sociolinguists. It is quite possible that English will continue to play a role in China's engagement with the world. Under these circumstances, English Language Teaching (ELT) in China is experiencing unpretending challenge ever before.

One of the fundamental issues, as the author of this paper believes, is the perspective towards English. Thus this paper tries to situate ELT in China in a global context of wider discussions in the closely related research paradigms of English language. The three influential perspectives in linguistic research adduced are a) $\mathrm{ENL} / \mathrm{ESL} / \mathrm{EFL}$ distinctions; $\mathrm{b}$ ) Inner/outer/expanding circles distinction; and c) world language system theory.

\section{ENL/ESL/EFL Distinctions}

One of the early attempts to account for systematic variation in the way English is used by speakers in different parts of the world is a tripartite distinction between English as a Native Language (ENL), English as a Second Language (ESL), and English as a Foreign Language (EFL) (Quirk, Greenbaum, Leech, \& Svartvik, 1985; Conrad, 1996). Based on this classification, Stern (1983), Widdowson (1997, 2003), McArthur (1998), Nunan and Carter (2001), among many other scholars, have proposed definitions and discussed the importance of these distinctions. Some other linguists (see, e.g., Görlach, 2002, pp. 99-117), have also tried to tackle theoretical issues arising from the use of these terms from a plualcentric perspective towards English varieties.

Crystal (2012) provides a picture to help visualize the way English is used as a native language around the world at the time of writing (Figure 1). Countries in red are places where English is used as mother tongue or native language. Counties in purple represent places where English is used as an official language. The places in green, as proposed by Crystal, are places where English is used as a mother tongue, but co-exists with other languages. He does not explain whether it is implied that the places besides these three colored zones (which obviously constitute a larger territory compared to the above-mentioned) could be characterised as places where English is used as a foreign language. 


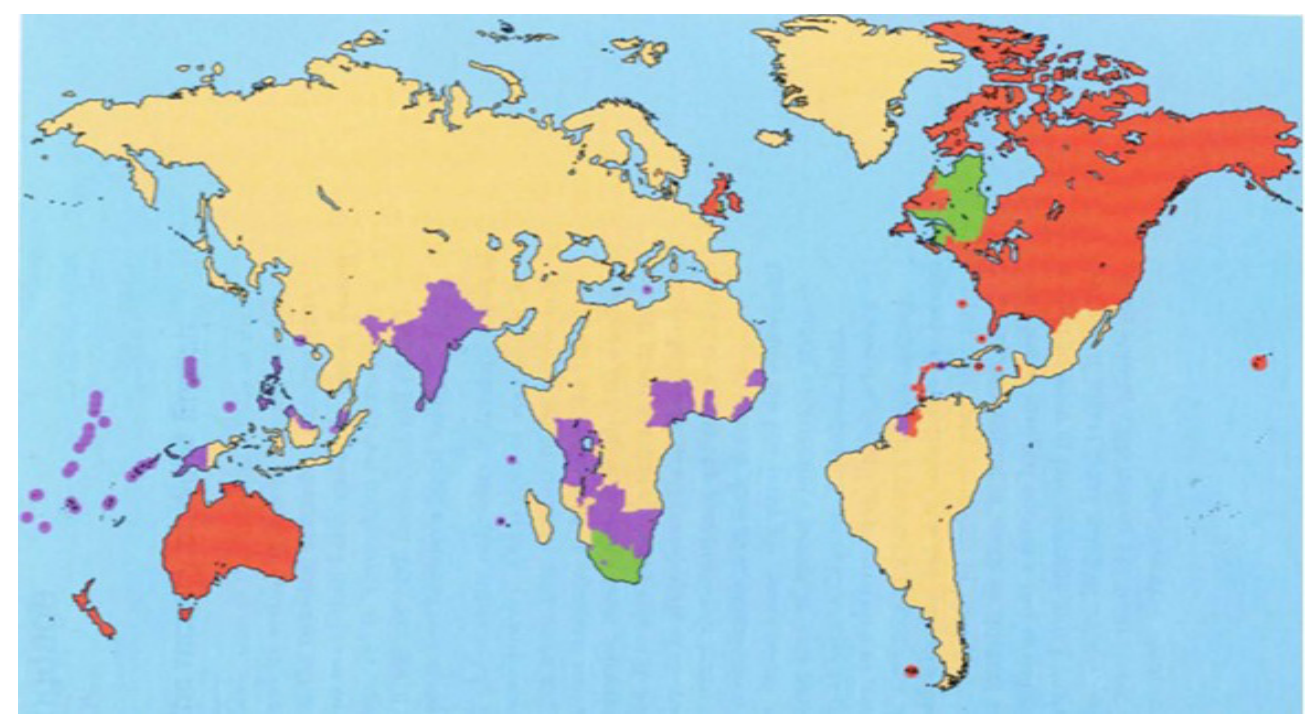

Figure 1. English used around the world as native or official language (Crystal, 2012, p. 152)

There is no doubt that this 'ENL/ESL/EFL distinction' has been helpful in certain contexts, but it has its shortcomings. One obvious drawback is that the notion native versus second and foreign indicates considerable linguistic prejudice against the latter terms, which might imply that one is superior and the others should look up to it as a standard. Another disadvantage may be that it is increasingly difficult to find countries that can be accurately classified as using EFL. How can one possibly distinguish 'second' from 'foreign' in the $21^{\text {st }}$ century, with the internet, Wi-Fi, Facebook, and built-in smartphone functions such as WhatsApp creating such readily accessible communication platforms connecting people regardless of the physical distance between them? For example, when surfing the internet and using communication tools like Facebook, people might use English most of the time. How can we define one user of this kind in Singapore as an ESL user while another in China as an EFL user?

Consider the case of one ordinary child in Guangzhou City, Mainland China, where he/she usually learns to speak his/her mother tongue (Cantonese) around one year old. And immediately after that, he/she would most probably be sent to Early Education Center/Early Childhood Development Academy for pre-primary tutoring activities, for example Disney English, iKid English, iBaby English, etc., where English is taught, with Mandarin as the medium of instruction. In such cases, English and Mandarin are acquired quasi-simultaneously, making it difficult to assign the term EFL and ESL to young people growing up with such experiences. The term ENL is another problematic label in a setting like Mainland China. Take the case of 'foreign experts' teaching English in China. It matters more to students, and their parents, that the foreign experts are proficient in English, regardless of whether they are ENL speakers from UK, USA, Canada, Australia or New Zealand. Usually the tutors in the language training schools/centers come from all over the world: Singapore, Europe and Africa, for example. The term 'native' is not as important as the fact that they can speak fluent English, which caters to the needs of the parents who pay for the courses.

These examples show how futile (and sometimes meaningless) the ENL/ESL/EFL distinction is to the general public, even though such a three-fold distinction or classification is well motivated theoretically speaking in research on the spread of English worldwide. So in the field of ELT, such a tripartite distinction is still widely acknowledged and held to be important by many scholars.

\section{Inner/Outer/Expanding Circles Distinction}

An alternative and equally influential classification of English, the inner/outer/expanding circles distinction, has been put forward by Kachru (1982) and supported by many others.

Braj Kachru's pioneering 'three concentric circles' model (1982, 1985, 1986, 1990, 1996, 2005), representing the growth and spread of English in the world, has been invaluable for researchers in the field of World Englishes (WE) to come to grips with the implications of the pervasive, highly complex and infiltrating presence of English in this second decade of the twenty-first century. In order to help build a better understanding of the use of English in different countries, Kachru (1985) elaborated the three-concentric-circles model of World Englishes in this way: 
"The current sociolinguistic profile of English may be viewed in terms of three concentric circles... The inner circle refers to the traditional cultural and linguistic bases of English. The outer circle represents the institutionalized non-native varieties (ESL) in the regions that have passed through extended periods of colonization...The expanding circle includes the regions where the performance varieties of the language are used essentially in EFL contexts" (pp. 366-367).

While the 'three concentric circles' model is not the only theoretical account of the tremendous variation and spread of English worldwide, it is certainly the most influential, and its impact may be felt and tracked in research on WE in the last three decades and, more recently, English as a lingua franca (ELF). Englishes in different countries and regions are increasingly regarded as "pluricentric languages" (Clyne, 1992), a view which is perfectly compatible with the World Englishes perspective. Kachru explains his reason for the three-circle classification in this way:

"The situation of English is historically and linguistically interesting and complex. First, the number of non-native speakers of English is significant; second, the spread of English is unique. The large range of varieties of English cannot be discussed from any one point of view. There are several, mutually non-exclusive ways to discuss their form and function" (Kachru, 1982, pp. 36-37).

Kachru has been advocating this view since the mid-1960s, when he pointed to the 'Indianness' of Indian English (1965, p. 391). His contribution attracted considerable scholarly attention in the 1970s, when two important international conferences were held which independently focused on a shared theme: the features and functions of the English varieties used in non-native speaking countries. One was organized at the East-West Culture Learning Institute of the East-West Center, Hawaii, and the other at the University of Illinois at Urbana-Champaign, resulting in the publications English for Cross-cultural Communication (Smith, 1981) and The Other Tongue: English across Cultures (Kachru, 1982), respectively.

Since then, the study of varieties of English, known as World Englishes, has become "a new sub-discipline of English linguistics" (Schneider, 2003, p. 234). The plural form 'Englishes' symbolizes "variation in form and function, use in linguistically and culturally distinct contexts, and a range of variety in literary creativity...it stresses the 'WE-ness' among the users of English, as opposed to us versus them (native and non-native)" (Kachru, 1996, p. 135).

For decades, this has been considered an influential model (e.g., Streven's World Map of English (1980), McArthur's Circle of World English (1987), and Görlach's Circle Model of English (1990)) that accounts for the processes as well as the outcomes of the spread of English to date. However, this paper follows Kachru's model, where the inner circle refers to the traditional cultural and linguistic bases of English, namely the USA and the UK, Canada, Australia and New Zealand. The outer circle includes countries where English is not the native tongue, but is important and plays a part in the nation's institutions, either as an official or national language (e.g., India, Nigeria, Singapore, the Philippines, Pakistan). The expanding circle includes the regions where the performance varieties of the language are used essentially in lingua franca contexts, for example, China, Egypt, Japan and Korea.

Though it is not possible to calculate populations of speakers of the three circles, estimates have been attempted in different ways. One example of this is from Crystal (1997):

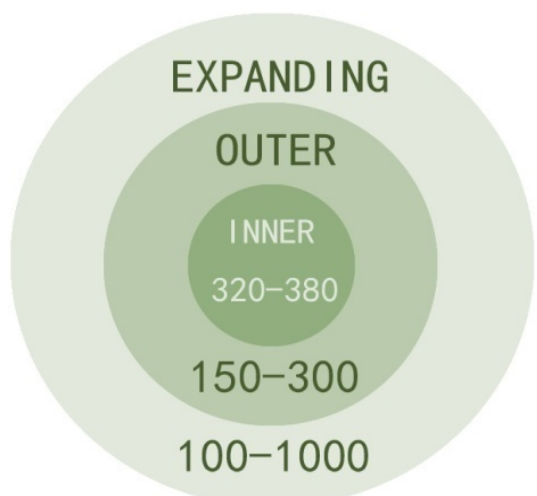

Figure 2. Graphic representation of the "Three Circles" model of English Speakers (in millions) (adapted from Crystal, 1997, p. 54) 
These numbers of speakers are largely underestimations now, because they were cited over 15 years ago. Reliable updated numbers for the three circles of speakers are not easily obtainable. Some reasons are rather obvious. For the number of speakers in the inner circle, the differences of options as to which countries/regions should be included under that heading will probably be a key reason that hinders the counting. The total number of expanding circle speakers are even more difficult to be sure about, for the obvious reason that fluency is a continuum whereby people will differ in their view about how much competence of English a person needs before being counted as a member of the community of expanding circle users. This is probably why the numbers in Figure 2 are still widely cited even today.

The evolving nature of the English language nowadays has called for a reassessment of a number of key dimensions in the analysis of English varieties. The foregoing discussion in regard to the question "what form English should (or is likely to) take as a model to follow' has become a naïve yet crucial question to answer. Which groups are empowered and which ones disadvantaged? Why? Should we or should we not accept that fact, namely that "People from the so-called 'core' English speaking countries are now in the minority among English users and 'native-speakers' of the language no longer determine how the language is being used internationally" (Clyne \& Sharifian, 2008, p. 281)? Would people from the inner circle countries feel upset by statements such as "English is now a new phenomenon, and if it represents any kinds of triumph it is probably not a cause for celebration by native speakers" (Graddol, 2006, p. 11)? These are among those questions that we can start asking; when we accept a World Englishes perspective toward today's Englishes.

\section{Peripheral/Central/Supercentral/Hypercentral Languages Distinctions}

Besides its global significance in terms of its functions and status, English is also thought to play a key role in the "global language system" (de Swaan, 2001, pp. 1-4). According to the "global language system" theory, the world's languages are hierarchically connected as one system, in that they fall into a pyramid-like hierarchy constructed by four levels. They are named as the peripheral, central, supercentral and hypercentral languages, with peripheral languages being situated at the lowest level of the hierarchy, serving principally as "languages of conversation and narration rather than reading and writing, of memory and remembrance rather than record" (p. 4). According to de Swaan, $98 \%$ of the world's languages are peripheral languages used by less than $10 \%$ of people in the world today. It is foreseeable that, being used by native speakers in particular areas (e.g., Jun dialect in China is estimated as spoken by only thousands of people in remote areas around South-east China) of the world, peripheral languages are at risk of falling out of use and facing the danger of extinct. At the same time, with increasing globalisation, more and more speakers of peripheral languages acquire more central languages in order to communicate with others. The next level — central languages - is constituted by 100 languages, which are spoken by about $95 \%$ of the world's population and generally used in the domains of education, public media and administration, and which typically serve as the national/official language(s) of the ruling state. Central languages are "languages of record: much of what has been said and written in those languages is saved in newspaper reports, minutes and proceedings, stored in archives, included in history books, collections of the 'classics', of folk talks and folk ways, increasingly recorded on electronic media, and thus conserved for posterity" (ibid, p. 5). Taking the society as a whole, many speakers of central languages become multilingual eventually. Because they are either native users of one particular peripheral language who have learned a central languages or native speakers of a central language and have acquired a supercentral language, the latter being situated at the second-highest level of the language hierarchy. Supercentral languages are usually widely-used languages that serve as connectors between users of central languages (i.e., Arabic, Chinese, English, French, German, Hindi, Japanese, Malay, Portuguese, Russian, Spanish, Swahili, \& Turkish, de Swaan, 2001, p. 5). Colonial traces for these languages could usually be observed. In other words, they "were once imposed by a colonial power and after independence continued to be used in politics, administration, law, big business, technology and higher education" (ibid, p. 5). The "world language system' theory proposes that, at the upper-most level is the language which connects speakers of the supercentral languages - the hypercentral language which "holds the entire world language system together. Currently, this hypercentral language is English" (ibid, p. 17). As such, the world's individual multilinguals are connected in a markedly hierarchically structured pattern. Though de Swaan's theory of the world's language system has been critiqued, with various scholars expressing concerns about its lack of a solid, empirically-grounded theoretical foundation (e.g., Morris, 2004; Phillipson, 2004), his conceptualization of a hierarchical pyramid of the languages of the world still represents an influential perspective of how natural languages are related in one world language system. At the same time, de Swaan provides a theoretical account on how English may link up individual multilingual whose L1 is not English, thereby placing English in an (especially IT-mediated) functional position, which complements the communicative functions of English as seen from the conceptual lens of Kachru's 
nations-based concentric circles of English.

To conclude, the 'ENL/ESL/EFL' and the 'inner/outer/expanding circles' distinctions, as well as the 'global language system' theory are equally important in their own ways, and none of them should be judged intuitively to be more valid than the other. Obviously, some countries and speakers in these classification models would inevitably overlap. They are by no means mutually exclusive; quite the contrary, insights obtained in one tend to enlighten or inform further research in the other.

\section{Implications for ELT in China}

Taking into account the complexity of the global spread of English language itself, plus the changing contexts where it is being used, we have to accept pluricentricity in English language as well as ELT. Pluricentricity means the dual acceptance of new varieties and their indigenized standards to linguistic studies, and means multiple acceptances towards teaching targets as well as learner outcomes. This is especially crucial for ELT in China.

The first reality teachers and learners have to face is that they have to be aware of linguistic variability. First, teachers/users of English in China should know that variability is a fact of life when it comes to real language use. One obvious example is pronunciation, as pointed out by Nelson (2011):

It is clear from casual observation and from what we all learned in our required courses in introductory linguistics or basic phonetics that it is at least highly unlikely that any two speakers pronounce the same word the same way, or even that the same speaker ever pronounce the same word the same way again. This is naturally true of 'native speakers' as well as 'non-native speakers'. That being so, why is anyone surprised that speakers of different varieties of English do not pronounce words in the same way? This very noticing of mismatches between what we hear and what we think we produce ourselves tells us that we do not expect or need identity of segmental pronunciations from all participants to make their speech intelligible or to make ourselves intelligible to others (Nelson, 2011, p.29).

One benefit of being aware of linguistic variability is that learners/users can have a guilt-free position without having to worry about whether their English is non-standard, partly because of their limited command of linguistic resources, and partly because they would feel more comfortable when engaged in naturally occurring meaning-making activities.

The second implication of accepting pluricentricity in English is the need to get rid of possible linguistic prejudice that people can't help holding. While an awareness of variability in English helps strengthen one's confidence and sense of language identity, linguistic prejudice is bound to arise, and is something to avoid through awareness-raising. Getting rid of linguistic prejudice is both an important task for people outside China and inside China. For example, the majority of non-native teachers of English should be aware that when their students are neither fulfilling a "patriotic enterprise" (Gao, 2012, p. 351) nor being perfect in English, something more than a standard/norm should be considered in the process of teaching and learning: the lingua-cultural identity of both the teacher and students should also be taken into consideration.

A third implication that could be drawn from the ideology of pluricentricity of classifying English language where the variability of the English is recognized and highlighted is that, English is not a single, homogenous, monolithic variety. Thus the Polymodel Approach (Kachru, 1992, p. 66) should be used to replace the Monomodel Approach in ELT practice in China. The issues of deciding and identify the most appropriate norms and models for ELT pedagogies are of special significance in China for at least two reasons. First, China has the largest English-learning and using population. Second, this population is used to speaking China English with cross-linguistic influences from Chinese, their mother tongue (He \& Zhang, 2010, p. 770). Diversified pedagogic models are eventually needed to be included into the considerations of not only language policy makers but also classroom teachers of ELT in China. 'Endonormative model' (Kirkpatrick, 2007, p. 189) with recognitions to variability in English is more suitable in today's English teaching pedagogy.

In sum, linguistic paradigms today provide the possibility of recognizing the pluricentricity which suit users of English in China in easing their way of learning to use the Language. More importantly, pluricentricity in classifications of English language allows learners of English a 'speaker identity' while learning and using the language at the same time. From this point, the significance of the pluricentric perspectives of classifying English to English language teaching in the Chinese contexts emerges.

\section{Acknowledgement}

This paper is funded by Guangdong Planning Office of Philosophy and Social Science (Project No.GD12XWW08). 


\section{References}

Conrad, A. W. (1996). The international role of English: the state of the discussion. In J. A. Fishman, A. W. Conrad, \& A. Rubal-Lopez (Eds.), Post-imperial English: Status change in former British and American colonies 1840-1990 (pp.13-36). Berlin: Mouton de Gruyter.

Clyne, M. (1992). Pluricentric languages: Differing norms in different nations. Berlin: Mouton de Gruyter.

Clyne, M., \& Sharifian, F. (2008). English as an international language. Australian Review of Applied Linguistics, 31(3), 281-296. http://dx.doi.org/10.2104/aral0828

Crystal, D. (1997). English as a global language. Cambridge: Cambridge University Press.

Crystal, D. (2012). A global language. In P. Seargeant, \& J. Swann (Eds.), English in the world: History, diversity, change (pp. 151-177). London: Routledge.

De Swaan, A. (2001). Words of the world: The global language system. Cambridge: Polity Press.

De Swaan, A. (2010). Language systems. In N. Coupland (Ed.), The handbook of language and globalisation (pp. 57-76). Malden: Wiley-Blackwell.

Gao, X. S. (2012). The Study of English in China as a patriotic enterprise. World Englishes, 31(3), 351-365. http://dx.doi.org/10.1111/j.1467-971X.2012.01762.x

Görlach, M. (1990). Studies in the history of the English language. Heidelberg: Carl Winter.

Görlach, M. (2002). Still more Englishes. Amsterdam: John Benjamins.

Graddol, D. (2006). English next. London: British Council.

He, D., \& Zhang, Q. (2010). Native speaker norms and China English: From the perspective of learners and teachers in China. TESOL Quarterly, 44(4), 769-789. http://dx.doi.org/10.5054/tq.2010.235995

Kachru, B. B. (1982). The Other Tongue: English across Cultures. Oxford: Pergamon.

Kachru, B. B. (1992). The Other Tongue: English across Cultures (2nd ed.). Urbana, IL: University of Illinois Press.

Kachru, B. B. (1985). Standards, codification and sociolinguistic realism: The English language in the outer circle. In R. Quirk, \& H. G. Widdowson (Eds.), English in the world: Teaching and learning the language and literatures (pp. 11-30). Cambridge: Cambridge University Press.

Kachru, B. B. (1986). The alchemy of English: The spread, functions, and models of non-native Englishes. Oxford: Pergamon Press.

Kachru, B. B. (1990). World Englishes and applied linguistics. Studies in Linguistic Sciences, 19(1), 127-152.

Kachru, B. B. (1996). World Englishes: Agony and ecstasy. Journal of Aesthetic Education, 30(2), 135-155.

Kachru, B. B. (2005). Asian Englishes: Beyond the canon. Hong Kong: Hong Kong University Press.

Kirkpatrick, A. (2007). World Englishes: Implications for international communication and English language teaching. Cambridge: Cambridge University Press.

McArthur, T. (1987). The English Languages? English Today, 3(3), 9-13.

McArthur, T. (1998). The English Languages. Cambridge: Cambridge University Press.

Nelson, C. L. (2011). Intelligibility in world Englishes: Theory and application. New York: Routledge.

Morris, M. (2004). Words of the World: The Global Language System by Abram de Swaan. Language in Society, $33(4), 620-624$.

Nunan, D., \& Carter, R. (2001). The Cambridge guide to teaching English to speakers of other language. Cambridge: Cambridge University Press.

Phillipson, R. (2004). English in globalization: Three approaches. Journal of Language, Identity \& Education, $3(1), 73-78$.

Quirk, R., Greenbaum, S., Leech, G., \& Svartvik, J. (1985). A comprehensive grammar of the English language. Harlow: Longman.

Schneider, E. W. (2003). The dynamics of New Englishes: From identity construction to dialect birth. Language, 79(2), 233-281.

Smith, L. E. (Ed.). (1981). English for cross-cultural communication. London: Macmillan. 
Stern, H. H. (1983). Fundamental concepts of language teaching. Oxford: Oxford University Press.

Strevens, P. (1980). Teaching English as an international language. Oxford: Pergamon.

Widdowson, H. (1997). EIL, ESL, EFL: Global issues and local interests. World Englishes, 16(1), 135-146.

Widdowson, H. (2003). Defining issues in English language teaching. Oxford: Oxford University Press.

\section{Copyrights}

Copyright for this article is retained by the author(s), with first publication rights granted to the journal.

This is an open-access article distributed under the terms and conditions of the Creative Commons Attribution license (http://creativecommons.org/licenses/by/3.0/). 